\section{Synliggørelse af proveniens i Det Kongelige Biblioteks bøger}

\author{
af lasesalskoordinator Jarle Rui Aadna
}

\section{Baggrund}

I 1970'erne blev Det Kongelige Bibliotek udsat for tyveri af bøger, fortrinsvis fra bibliotekets ældre samlinger. Som følge heraf gennemførte biblioteket en række sikkerhedsmæssige foranstaltninger, som medvirkede til, at tyverierne ophørte. ${ }^{1}$ I efteråret 1978 blev der truffet beslutning om, at der skulle iværksættes en totalrevision af Udenlandske Afdelings Ældre Samling (UAÆS) fra 1531-1949, som omfattede ca. 22.600 hyldemeter bøger. ${ }^{2}$ Arbejdet begyndte i 1979, og pågik med visse afbrydelser frem til $1999 .^{3}$

Under planlægningen af revisionen blev det besluttet, at man under arbejdet med at sammenholde katalog og hyldebestand ikke skulle nøjes med at registrere tilstedeværelsen (eller ej) af hvert bind. Ud over den blotte konstatering af mangler og isætning af etiketter med fortrykt stregkode i de korrekt forefundne bøger, blev der også indsamlet - til senere brug - grundlæggende data om bøgernes fysiske tilstand, og om eventuel nødvendig udtagning til sikringsrum. Endelig blev det besluttet, at man også - når man nu alligevel havde bogen $\mathrm{i}$ hånden - skulle notere boghistoriske karakteristika såsom usædvanligt udstyrede bogbind og ejermærker i form af navne, initialer eller symboler af forskellig slags. ${ }^{4}$ Oplysningerne blev indført med sirlig pen i de såkaldte røde lister, som de fortrykte inddateringsprotokoller blev kaldt. Der var kolonner til katalog- og sidenummer, løbenummer, trykkeår, samt for låners navn, hvis bogen var udlånt. I kolonnerne længst til højre blev der inddateret oplysninger om eventuel tilstedeværelse i indbindingen af fragmenter af middelalderlige pergamentmanuskripter, om omfattende håndskreven annotation $\mathrm{i}$ bogen, $\mathrm{og} \mathrm{om}$ exlibris, super-exlibris og håndskrevne ejermærker.

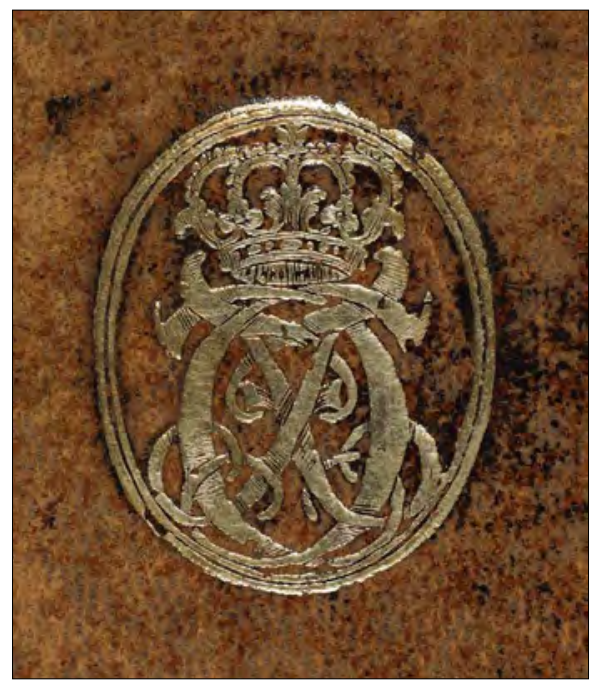

Fig. 1: Hertug Carl Friedrich (17001739) af Gottorps super-exlibris.

rbejdet med de ca. 200 kataloger
afstedkom en liste over manglen-
de bøger, der sidenhen blev samlet $\mathrm{i}$ et Excel-skema og udgjorde grundlaget for eftersøgning og genanskaffelse af nogle af bibliotekets egne eksemplarer og mange erstatningseksemplarer. De under revisionen indklæbede stregkoder 
i bøgerne har gjort det betydelig lettere at udføre stikprøverevisioner og i det hele taget at holde orden i magasinerne. Men hvad med de mange boghistoriske data som kunne fortælle historier om tidligere ejere, læsere og ekstraordinære bogbind?

\section{Boghistoriske detaljer}

Da revisionen i 1999 var vel overstået, blev de rode lister lagt til side i over ti år, og med dem de boghistoriske detaljer. Overarkivar Ivan Boserup fra Håndskriftsafdelingen, som i sin tid var med til at planlægge revisionen, "gen-erindrede" imidlertid de ubenyttede data i de røde lister og gik i 2010 forsøgsvis i gang med at inddatere tidligere ejere i katalogposterne. I maj 2011 gjorde han undertegnede opmærksom på listernes eksistens, og han foreslog, at personale knyttet til Forskerlæsesalen, Læsesal Vest, som er vant til at omgås de ældre bogsamlinger, kunne have det som opgave, når tjenesten tillader det, at påbegynde en inddatering af disse data. Der blev så bestilt et mindre antal revisionsprotokoller frem, så vi kunne se nærmere på dem og tilrettelægge de nødvendige procedurer.

Tanken var at dele de mange boghistoriske data med brugere og forskere, og en måde at gøre det på ville være at inddatere oplysningerne i de respektive poster i REX, hvor såvel personale som brugere vil kunne se dem. Efter en del forsøg landede vi på en standardprocedure for, hvordan de boghistoriske data mest hensigtsmæssigt kunne inddateres. Proveniensdata bliver i et for brugerne skjult felt inddateret nøjagtigt som de blev indskrevet af de mange forskellige medarbejdere i revisionsperioden 1979-99. Således kunne man ved even- tuel mistanke om unøjagtigheder eller utydeligt ophav hurtigt finde frem til registreringens oprindelige ordlyd. Det andet felt skulle være ansigtet udadtil, med kortfattede biografiske oplysninger om den tidligere ejer. Til dette felt ville vi anvende en for Det Kongelige Bibliotek ny udvikling af MARC-formatet: Funktionskoder føjet til navneformer (illustrator, oversætter, redaktør, etc.); i den aktuelle sammenhæng koden for "Tidligere ejer", fmo (= former owner). I et tredje, også for brugerne synligt felt, skulle posten beriges med oplysninger om særheder ved bogbind, håndskrevne noter, pergamentfragmenter m.m.

\section{Forløbet}

Læsesal Vests personale gik i gang med inddatering af de mange oplysninger som en såkaldt back office-opgave. De

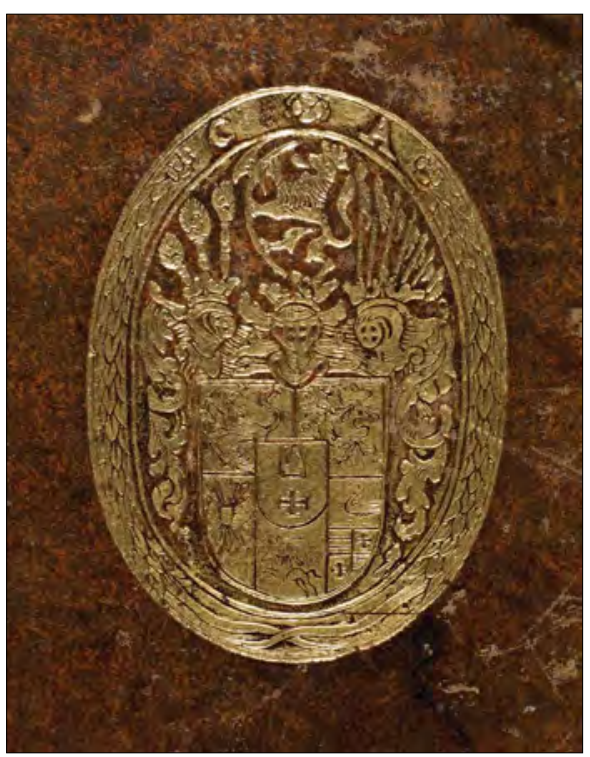

Fig. 2: Hertug Christian Albrecht (16411694) af Gottorps super-exlibris. 
håndskrevne registreringer var normalt lette at tyde, men i visse tilfælde blev vi nødt til at konsultere det fysiske eksemplar for at kunne afkode forkortelser eller for med egne øjne at se ejermærket. Under registreringen af bøger fra Gottorp Slot havde man under revisionen ikke sondret mellem de forskellige super-exlibris, der angiver under hvilken hertug, bogen blev indbundet. I disse tilfælde tilstræbes det at få set samtlige bind, så der kan skelnes mellem de forskellige hertugelige våbenvarianter. ${ }^{5}$

Ved nogle revisionsnumre i protokolkolonnen bemerkninger var noteret et spørgsmålstegn, hvilket angiver, at ophav eller tidligere ejer ikke var kendt ved registreringens tidspunkt. Disse spørgsmålstegn har pirret personalet til at forsøge at knække de gåder, som der hverken var tid eller hjælpemidler til under revisionsarbejdet i magasinerne. Der er megen hjælp at hente i de mange opslagsværker opstillet på Forskerlæsesalen og i Center for Manuskripter og Boghistorie. Dertil kommer, at proveniens og internettet er en frugtbar cocktail, som kan give adækvate ledetråde og fingerpeg. Onlineudgaven af C.F. Brickas Dansk biografisk Lexikon er således et nærmest uundværligt hjælpemiddel. ${ }^{6}$ Der er også megen ekspertise at trække på i Det Kongelige Bibliotek, både blandt ansatte og domicilerede forskere. Dersom vi med en given proveniens ikke kommer videre, konfererer vi også gerne med Forskerlæsesalens brugere. Hvis dette heller ikke giver et sikkert resultat, gemmer vi en afbildning af ejermærket sammen med katalogsignaturen til senere granskning.

Endvidere har vi registreret en brugerkonto hos CERL (Consortium of
European Research Libraries), hvortil man kan uploade fotografier af initialer og ejermærker, man ikke umiddelbart er i stand til at identificere. ${ }^{7}$ Med tiden vil forhåbentlig flere proveniensforskere og personalhistorikere kunne identificere ejermærker, som vi foreløbigt har måttet lægge til side. Vi har således allerede været i dialog med flere andre, der forsker i bibliotekshistorie.

\section{Bind og ejermærker}

Forskningsbibliotekar og historiker Harald Ilsøe har i Det kongelige Bibliotek $i$ støbeskeen kortlagt samlingernes historie ved mange eksempler, men naturligvis ikke udtømmende, ${ }^{8}$ og vores arbejde kan derfor ses som en uddybning af Ilsøes pionérarbejde.

Under inddateringen støder vi ind $\mathrm{i}$ mellem på ejermærker som vi vælger at affotografere med tanke på publicering på Det Kongelige Biblioteks proveniensside Royal Identification Marks. ${ }^{9}$ Eksempelvis kan nævnes de forskellige varianter af dronning Juliane Maries (1729-1796) monogrammer samt etatsråd og bogsamler Holger Thotts (1647-1695) superexlibris. Kriterier for publicering har

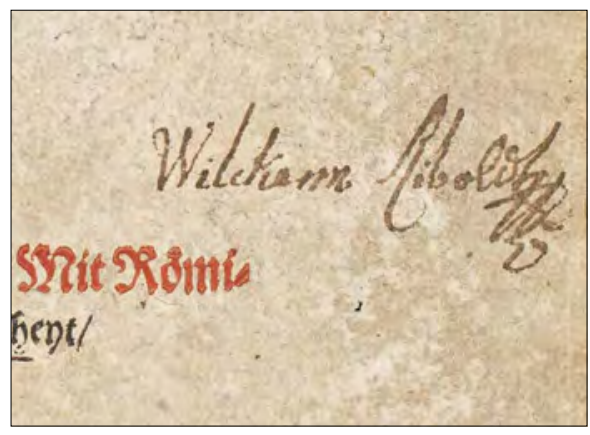

Fig. 3: Maleren Wilchen Riboldts (1661-1711) signatur. 


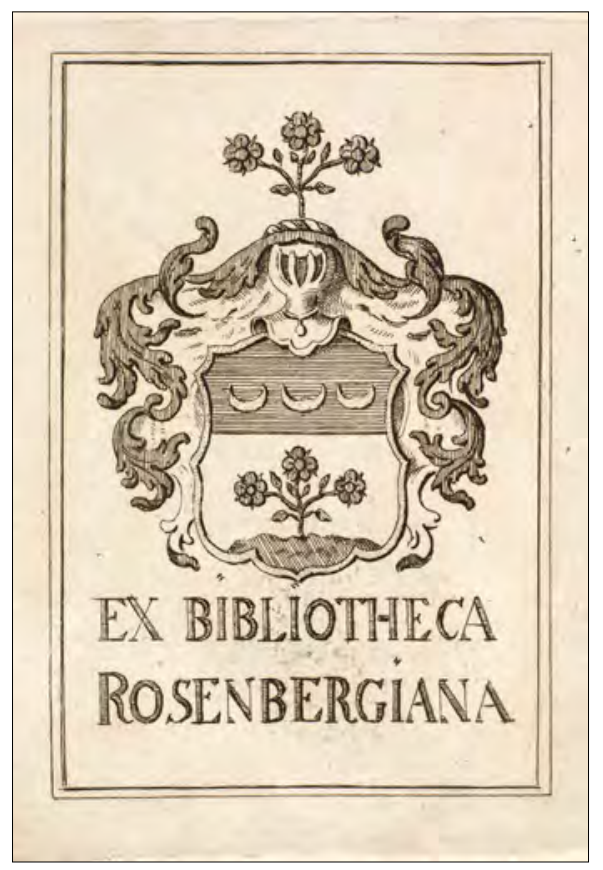

Fig. 4: Ex Bibliotheca Rosenbergiana:

Henryk Wilhelm Rosenbergs (1711-1794) exlibris.

hidtil været, at Det Kongelige Bibliotek skal have en større del af vedkommendes bogsamling. Denne bestemmelse forekommer forældet i dag: Det primære formål med Royal Identification Marks, der blev udviklet på kort tid, var at tillade boghandlere og auktionshuse at slå op og se - ud fra bind og ejermærketyper, - om en given bog kunne være stjålet fra Det Kongelige Bibliotek.

Mange af ejermærkerne har dansk tilknytning, som i tilfældet hvor maleren Wilchen Riboldt (1661-1711) har sat sin signatur på titelbladet. Længere inde i bogen er der også skitser og farvelægninger sandsynligvis foretaget af samme pen.

Der findes også mange bøger, som har haft udenlandske ejere. En af disse er den bøhmiske adelsmand Peter Wok von Rosenberg (1539-1611) hvis bøger har fundet vej til Det Kongelige Bibliotek. Han er i Danmark mest kendt som vært ved Tycho Brahes sidste, offentlige middag. Andre er humanisten og rejseskribenten Giacomo Castelvetro (1546-1616), ${ }^{10}$ hvis signatur ses som Di Giacopo de Castelvetri. Der findes også exlibris tilhørende den kongelige rådgiver for August III af Polen, Henryk Wilhelm Rosenberg (1711-1794), samt for Hongkongs første guvernør, Sir Henry Pottinger (1789-1856) - for blot at nævne nogle få eksempler.

0 om indbinding ses en del middelalderfragmenter af pergament, ofte fra illuminerede (dekorerede) håndskrifter. I disse tilfælde er oplysningerne også inddaterede i REX til glæde for interesserede forskere, der via REX vil kunne finde materiale at arbejde

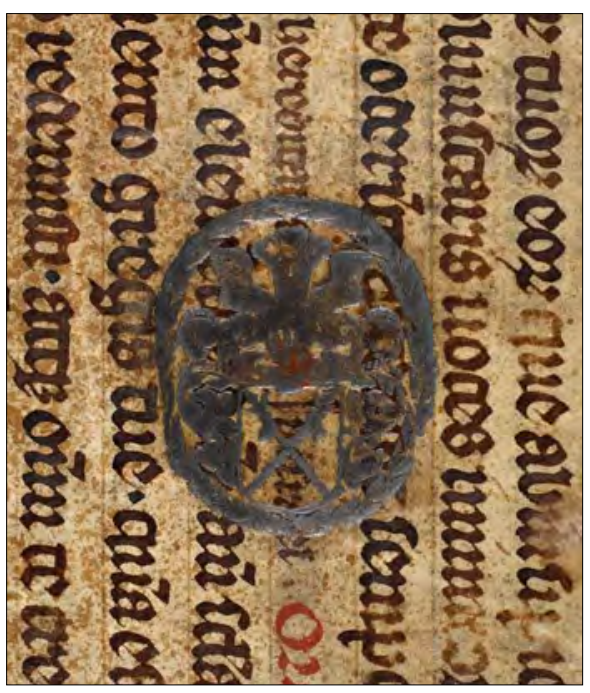

Fig. 5: Christian Herman Helwerskovs (1655-1733) super-exlibris på fragment. 


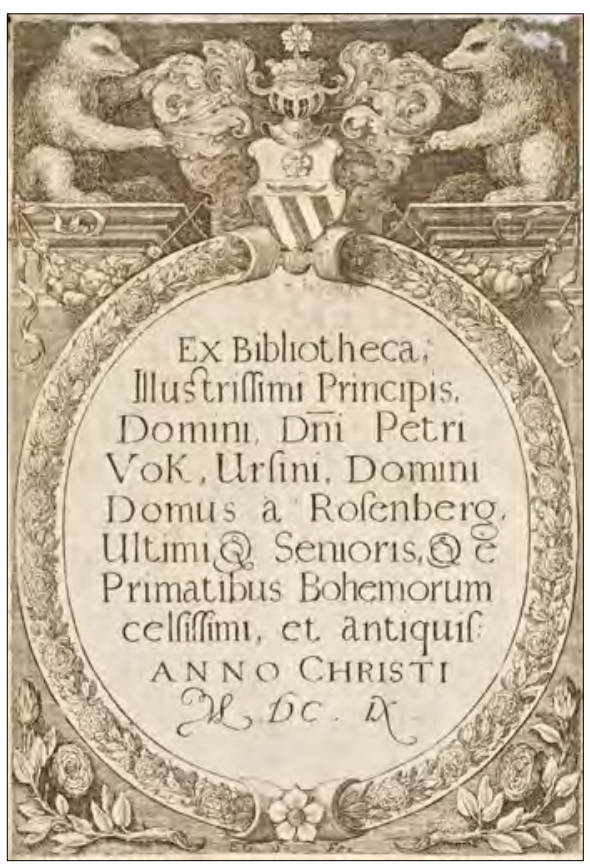

Fig. 6: Peter Wok von Rosenbergs (1539-1611) exlibris.

med, som aldrig har været kendt internationalt. I ét tilfælde har den danske justitsråd Christian Herman Helwerskov (1655-1733) ladet sit super-exlibris trykke ovenpå et håndskriftfragment, hvilket vidner om, at bogens ejerforhold har overtrumfet bog- og håndskrifthistoriske data, som i dag forekommer vigtigere at bevare i ubeskadiget tilstand. I flere tilfælde er tidligere ejeres navne sågar forsøgt visket ud eller overstreget.

\section{Fremtid og muligheder}

Pr. september 2012 er der i Proveniensprojektet inddateret over 6.500 ejerforhold og/eller andre bog- og bibliotekshistoriske data i Det Kongelige Biblioteks onlinekatalog REX. Kun de færreste revisionprotokoller er p.t. gennemgået, så store mængder data venter endnu på at blive gjort tilgængelige. Eftersom mængden af proveniensdata i dag bliver mere og mere tilgængelig igennem registrering i elektroniske bibliotekskataloger $i$ ind- og udland, gives der muligheder for nye kontekster og kombinationer. Selv de mindste boghistoriske data kan vise sig at være vigtige kilder til historien om bøger og biblioteker - og om deres læsere. ${ }^{11}$ Fremover vil det kunne tænkes at ikke kun boghistoriske data, men også fotografier af ejermærker og bind vil kunne knyttes sammen med katalogposter i onlinekatalogerne.

Endnu en udvidelse kunne være linkning af biografiske oplysninger til andre onlineressourcer som Dansk biografisk Lexikon og Allgemeine Deutsche Biographie. Mens vi venter på nye muligheder, er vi tilfredse med at kunne præsentere boghistoriske data i form af tidligere ejere og ekstraordinære bind i bibliotekskatalogen og på websider. De eksisterende data vil forhåbentlig beriges og suppleres med nye og endnu ikke registrerede data til glæde for alle som viser interesse for bogog bibliotekshistorie i bredeste forstand. 


\section{Noter}

1 <www.kb.dk/da/kb/manglende-boger/ baggrund/index.html>.

2 Det Kongelige Bibliotek, Interne meddelelser, 25. september 1978.

3 Opklaringen af bogtyverierne på Det Kongelige Bibliotek i 1970'erne. Redegørelse til Kulturministeriet: <www. $\mathrm{kb} . \mathrm{dk} /$ export/sites/kb_dk/da/kb/ manglende-boger/baggrund/baggrund/ opklaring-bogtyverierne.pdf>.

4 Det Kongelige Bibliotek: Arsberetning, 1999, s. 81.

5 Dieter Lohmeier: Die Gottorfer Bibliothek, s. 346-47 i Gottorf im Glanz des Barock, bd. 1, Schleswig, 1997.

6 C.F. Bricka: Dansk Biografisk Lexikon, 1. udgave: <runeberg.org/dbl/>.
7 Can you help? <provenance.cerl.org/cgibin/canyouhelp/start.pl>.

8 Harald Ilsøe: Det kongelige Bibliotek i støbeskeen. Studier og samlinger til bestandens historie indtil ca. 1780. København, 1999, I, s. 22.

9 Ved Signe Strecker: <www.kb.dk/en/nb/ tema/webudstillinger/Royal_Identification_Marks/Royal_monograms.html>.

10 Anders Toftgaard: Om Giacomo Castelvetros håndskrifter i Det Kongelige Bibliotek. Fund og Forskning, 50, 2011.

11 Ivan Boserup: Some new ways to identify prints with a Gottorp provenance in the Royal Library, Copenhagen, Virtual visits to lost libraries, London, 2011 (CERL Papers, XI). 